\title{
O Laptop Educacional na Escola: uma reflexão sobre inclusão digital
}

\author{
Cristina Maria Pescador, PGIE /UFRGS, cpescador@gmail.com \\ Jeronimo Becker Flores, PGEDU/UCS, jeronimobecker@gmail.com
}

Resumo: Este trabalho consiste em uma reflexão teórica, abordando questões sobre a Educação no contexto das tecnologias digitais e da inclusão digital. Parte-se de um pressuposto teórico que vincula a inclusão digital ao exercício da cidadania no contexto digital, argumentando-se que a promoção desse tipo de ação necessita ultrapassar o âmbito do acesso à tecnologia digital, em busca do desenvolvimento de uma concepção de uso caracterizada pela criticidade, pela reflexão e pelo redimensionamento das práticas frente às realidades da cultura digital. As reflexões tomam por base dois modelos de ações que visam a incluir a escola na cultura digital: o modelo um computador para muitos e o modelo um computador para um (1:1). Em consonância com a base teórica considerada, ponderamos que o segundo modelo referido, presente no programa "Um Computador por Aluno" (UCA), tende a representar maiores possibilidades de inclusão digital. Sustentamos esse argumento postulando que o UCA ultrapassa a disponibilização da tecnologia digital, abarcando a esfera da promoção de concepções críticas e reflexivas de uso, por intermédio da formação de professores e gestores envolvidos.

Palavras-chave: educação; tecnologias digitais; inclusão digital.

\begin{abstract}
This paper is a theoretical reflection considering issues related to Education in the context of digital technologies and digital inclusion. We start from a theoretical point of view that links digital inclusion to the exercise of citizenship in the digital context. We argue that to promote this kind of action it is necessary to go beyond the access to digital technology, towards the development of a concept that considers the use characterized by criticism, reflection and restructuring of practices in face of digital culture. Reflections take into account 2 models of actions that aim at including schools into the digital culture: the model of one computer by many, and the model of one laptop per student (1:1). In consonance with the theory taken as basis, we carefully examine the latter, which is present in the "Programa Um Computador por Aluno - UCA (One Laptop per Student), and which seems to represent larger possibilities of digital inclusion. We support that argument assuming that UCA surpasses the availability of digital technology, including promotion of critical and reflexive conceptions of use, with education and development for teachers and school administrators involved in the process.
\end{abstract}

Keywords: education; digital technologies; digital inclusion.

\section{Introdução}

Desde os primórdios da década de 1970, autores como Alan Kay e Seymour Papert preconizam a possibilidade de utilizar computadores nas salas de aula como um fator provocador de mudanças na educação (Valente, 2011). No entanto, a simples inserção dos computadores não significa que haverá mudanças na maneira de se promover a Educação, nem tampouco que estaremos criando condições para favorecer o aprendizado de cada aluno. Nesse sentido, vale destacar que não se trata de reproduzir no computador as mesmas tarefas que eram feitas com lápis e papel.

Com a implantação do Projeto Um Computador por Aluno (ProUCA), em 2007, o Brasil introduziu, em caráter experimental, a primeira fase (pré-piloto) de laptops educacionais na modalidade 1:1 em cinco escolas brasileiras. Em 2010, teve início a segunda 
fase de implantação do ProUCA, com seis municípios brasileiros sendo contemplados com o ProUCA total (100\% das escolas públicas nessas cidades receberam os laptops educacionais) e 300 escolas em todo o Brasil selecionadas para o Projeto Piloto. Atualmente, terminadas as duas fases experimentais, a proposta transformou-se em Programa UCA em que os laptops, anteriormente doados às escolas, passam a ser adquiridos pelos municípios através de processo de licitação.

É nesse contexto que surge a proposta para este trabalho, cuja inspiração vem de debates de um grupo de pesquisa que atua junto ao ProUCA acompanhando duas escolas da rede pública na Serra Gaúcha. Dentre os objetivos da reflexão teórica aqui proposta, busca-se compreender a inclusão digital no contexto de ações educacionais observáveis no processo de implantação do ProUCA. Para tal, primeiramente consideram-se os argumentos propostos por Coscarelli e Ribeiro (2005) e Teixeira (2010), que vinculam a inclusão digital ao ato de partilhar da gama de direitos e deveres implícitos ao contexto digital e ao exercício da cidadania por intermédio dos recursos tecnológicos digitais, respectivamente.

Destarte, objetiva-se abordar criticamente o conceito de inclusão digital para, com essa base, tratar de dois modelos de ações de inserção das tecnologias digitais observadas nas escolas. Com fundamentação na visão teórica de autores como Schlemmer (2006), Almeida e Valente (2011), aborda-se o modelo de um computador para muitos, ação observada nos Laboratórios de Informática Educativa (LIEs). Na sequência, sob a chancela dos textos de Alarcão (2007) e Perrenoud (2000), considera-se a formação de professores proposta pelo UCA como um dos diferenciais do projeto, tornando a ação mais passível de prover a inclusão digital dos sujeitos e da própria escola no contexto digital.

Como última etapa, apresentam-se as percepções alcançadas durante 0 desenvolvimento desta reflexão teórica, com ênfase para a relevância da formação docente com uma concepção de professor reflexivo, promovendo o senso crítico e a reflexão sobre a ação. Também se destaca o fato de que o acesso à tecnologia digital não é condição suficiente para a promoção da inclusão digital, havendo a necessidade de um redimensionamento epistemológico.

O trabalho investe-se de relevância social, uma vez que as considerações aqui ponderadas podem provocar ecos nas ações educacionais, impulsionando a promoção da inclusão digital. As reflexões tratadas aqui podem suscitar o debate, levando outros pesquisadores a ampliarem, questionarem e problematizarem os argumentos aqui levantados, contribuindo para a reflexão crítica no contexto das tecnologias na educação.

\section{Inclusão digital: uma abordagem teórica}

Estamos vivendo em uma sociedade caracterizada pela cultura digital. Segundo Lévy (1999), essa cultura trouxe consigo novas práticas, valores, técnicas materiais e intelectuais e formas de pensamento. Podemos perceber quase que diariamente a constância das tecnologias digitais, como, por exemplo, no uso de um caixa eletrônico, nas facilidades de compras e pesquisas na $w e b$, na praticidade e múltiplas aplicabilidades da telefonia móvel. No entanto, precisamos destacar que essas oportunidades ainda não se estendem a toda a população, podendo significar exclusão para aqueles que não contam com a chance de interagir significativamente com o contexto digital.

A problemática relacionada à exclusão digital é passível de reflexão, sobretudo quando consideramos, assim como ponderam Coscarelli e Ribeiro (2005), que essa exclusão atinge de forma especial a escola. Coll et al (2010) esclarecem que, mesmo sem haver qualquer tecnologia digital dentro da escola, elas entram indiretamente, pois se fazem presentes nas mentes dos estudantes como algo que lhes é próprio. Analisando os argumentos dos autores, percebemos um desafio para a escola contemporânea: como estar incluída na cultura digital? 
Antes de buscarmos compreensões para a interrogação do último parágrafo, torna-se necessário definir o que entendemos como inclusão digital. Coscarelli e Ribeiro (2005, p.17), por exemplo, enfatizam que

inclusão digital é um processo em que uma pessoa ou grupo de pessoas passa a partilhar dos métodos de processamento, transferência e armazenamento de informações que são do uso costume de outro grupo, passando a ter os mesmos direitos e os mesmos deveres dos já participantes daquele grupo onde está se incluindo.

Partindo desses pressupostos teóricos, parece-nos que a inclusão digital não se relaciona apenas à disponibilização de recursos tecnológicos digitais, como o fornecimento de computadores e acesso à internet. Para propiciar a oportunidade de os sujeitos partilharem dos mesmos direitos e deveres dos demais já inclusos no contexto digital, recomenda-se o desenvolvimento do senso crítico e da reflexão sobre a ação no contexto digital.

Consoante com argumentos já elencados, Teixeira (2010) enfatiza que a inclusão digital abarca a dimensão do viver em sociedade, considerando processos de interação, ampliação da cultura e valorização da identidade, com o uso das tecnologias digitais para o exercício da cidadania ("cibercidadania”). Assim, promover o acesso à tecnologia digital e "instrumentalizar" o sujeito para o uso parece não ser o suficiente para a promoção da inclusão digital. Ponderamos que a inclusão digital se relaciona não apenas ao acesso, mas ao desenvolvimento de uma concepção crítica e significativa de uso.

De fato, o acesso à tecnologia digital é uma etapa relevante para a promoção da inclusão digital. Takahashi (2000) evidencia que setores sem esse acesso tendem a ficar prejudicados intelectual e financeiramente, pois estariam privados de uma série de oportunidades. Concordamos com os argumentos do autor, entretanto, oferecemos aqui um contraponto, postulando que, mesmo tendo acesso ao aparato digital, mas sem um uso competente e crítico, os setores tendem a permanecer em situação de exclusão. O aparato digital pode substituir outras tecnologias analógicas, como, por exemplo, o lápis, o ábaco e a máquina de escrever, sem representar o partilhar dos direitos e deveres dos cidadãos já inclusos ou o exercício da "cibercidadania".

Refletimos sobre a necessidade de ultrapassar a esfera do acesso, adentrando no âmbito do desenvolvimento de concepções e condições de uso. Consoante com essas ideias, Coscarelli e Ribeiro (2005, p.15) apontam que

\footnotetext{
é preciso ir muito além do aprender a digitar em um computador. Quando as pessoas em situação de exclusão social passam a ter acesso ao computador e seus recursos, pode-se falar em popularização ou mesmo em democratização da informática, mas não necessariamente em inclusão digital.
}

Segundo esses pressupostos teóricos, a promoção da inclusão digital não está relacionada apenas ao acesso à tecnologia digital, mas a algo mais amplo, onde o sujeito interage, critica, questiona e altera os cenários apresentados pelo contexto digital.

Considerando os argumentos mencionados anteriormente, no próximo item apresentamos uma ação educacional passível de promover a inclusão digital.

\section{O computador na escola e a inclusão digital}

Como já foi citado, a sociedade contemporânea segue um ritmo cadenciado pela cultura digital, com novas formas de pensar, agir e se relacionar. Percebemos informações que se entrelaçam em uma espécie de redimensionamento do tempo e do espaço. Entretanto, 
Alarcão (2001, p.15) destaca que "assiste-se hoje a uma forte inadequação da escola para fazer face às demandas da sociedade”. Mesmo tendo passado mais de uma década da publicação do texto da autora, aparentemente, a escola ainda permanece na contramão do ritmo da sociedade.

Políticas públicas e iniciativas privadas tentam erradicar a dicotomia entre escola e sociedade. Os discursos dessas ações, de forma geral, preconizam a promoção da inclusão digital. No entanto, o foco parece estar mais no acesso à tecnologia digital, não passando pelo desenvolvimento de uma concepção de uso. O que observamos, de um modo geral, são ações que contemplam a instalação de laboratórios de informática educativa (LIE), no modelo um computador para muitos.

Uma abordagem distinta em relação à inserção de computadores na escola está nas propostas do programa "Um Computador por Aluno" (UCA). Segundo a perspectiva de Egler e Costa (2010), o UCA visa a promover a inclusão digital dos estudantes e também de suas famílias, fornecendo um laptop educacional para cada estudante (modelo 1:1), proporcionando uma estrutura de apoio e formação para gestores e professores envolvidos. Essa formação não se limita ao âmbito técnico, abarcando a esfera pedagógica no sentido de redimensionar a escola frente à atual conjuntura de sociedade.

Dentre os diferenciais do UCA em relação a outras propostas, enfatizamos, de maneira especial, a formação docente. Professores e pesquisadores de Instituições de Ensino Superior (IES) formaram parcerias com as Secretarias de Educação, envolvendo profissionais dos Núcleos de Tecnologia em Educação (NTEs) e dos Núcleos de Tecnologia do Município (NTMs) em um esforço conjunto para, à época da formação (2010-2012), desenvolver uma formação continuada, calcada em aspectos como criticidade e constante atitude reflexiva.

Destacamos a formação docente como um elemento passível de promover alterações nos cenários pedagógicos da escola. Formar um professor reflexivo, na visão de Alarcão (2007), relaciona-se à tomada de consciência, ao diálogo e ao exercício da criatividade. Em uma realidade de cultura digital, parece ser adequado formar um professor com essas bases, que tenha a capacidade crítica, criativa, que dialogue com os demais sujeitos e situações. Um professor com tais características, aparentemente, está em condições de promover a inclusão digital.

Em contraponto, vale lembrar que nenhuma formação docente pode garantir alterações nos panoramas docentes do professor. Perrenoud (2000, p.160) reitera esses argumentos, destacando que "formar-se não é - como uma visão burocrática poderia, às vezes, fazer crer fazer cursos (mesmo ativamente); é aprender, é mudar, a partir de diversos procedimentos pessoais e coletivos de autoformação".

O autor é enfático ao destacar que a formação se relaciona a mecanismos pessoais e individuais de subjetivação. Nesse contexto, formar-se abarca a esfera da participação ativa, da crítica e das trocas colaborativas entre os pares. O autor ainda aponta a formação reflexiva como uma necessidade para a Educação contemporânea.

A configuração da formação docente proposta para os professores que atuam no UCA parece convergir com os argumentos propostos por Alarcão (2007) e Perrenoud (2000), ultrapassando a instrumentalização para o uso e adentrando no âmbito do desenvolvimento de uma concepção de uso, partindo da reflexão da própria realidade encontrada em sala de aula.

O programa UCA como um todo perpassou a disponibilização de computadores, abarcando a esfera da capacitação de professores e gestores para uma atuação articulada com o contexto da cultura digital. Esse tipo de ação parece tender a representar maiores possibilidades de inclusão digital. 


\section{A formação e capacitação de professores para o Projeto UCA}

Os professores das escolas gaúchas contempladas com o laptop educacional pelo Projeto UCA participaram de Curso de Formação, bimodal, organizado em 4 módulos, totalizando 180 horas, e hospedado em ambiente virtual de aprendizagem do e-proinfo sob a coordenação conjunta de professores e pesquisadores das IES parceiras e professores e técnicos vinculados aos NTEs ou NTMs.

Entre o grupo de formadores, trata-se de senso comum que os professores têm papel fundamental no processo de implantação dos laptops educacionais e, para isso, devem ser capacitados para saber usar os microcomputadores, desenvolver uma ação mais centrada no aluno, poder ajudá-lo e criar um ambiente de aprendizagem favorável ao uso dessas novas tecnologias (Valente, 2011.p.28).

Nesse sentido, a proposta de promover a capacitação e qualificação de gestores e professores das escolas participantes do Projeto UCA no uso da tecnologia digital parece estar em consonância com o papel que a tecnologia digital tem de "oferecer suporte ao novo paradigma de ensino" (Prensky, 2010. p.202). Para esse autor, o fracasso da experiência com laptops nas escolas americanas pode estar relacionado com o fato de que a tentativa tinha o objetivo de fazer com que os professores mudassem seu jeito de ensinar, sem promover discussões para que refletissem sobre prováveis mudanças no modo de aprender de seus alunos.

Prensky (op. cit) defende o uso das tecnologias digitais e interativas voltado para uma aprendizagem centrada no aluno, em que as crianças ensinam a si mesmas com a orientação do professor. Da mesma forma, Prado et al (2011, p.61) apontam a necessidade de "uma nova gestão da prática do professor, além de gerar novos desafios que levam a repensar o currículo".

Que mudanças estão sendo provocadas por causa da entrada dos laptops educacionais e do acesso à internet nas salas de aula? Concordamos com Coll e Monereo (2010) quando afirmam que, ao trazer as tecnologias de informação e comunicação (TICs) para a sala de aula, não são apenas os atores do cenário educacional que se modificam. "Os conteúdos, as modalidades de organização de tempo, espaço e recursos específicos” (op. cit, p. 30) também se modificam, levando os processos educacionais a ultrapassar as paredes da escola, trazendo para a sala de aula aspectos que fazem parte do "mundo real" dos nossos alunos. Preferimos, por isso, o termo "Tecnologias Digitais de Informação e Comunicação" (TDICs), pois concordamos com Almeida (2010) em seu argumento de que esse termo é mais abrangente, envolvendo um conjunto de recursos e aplicações que se utilizam da internet para sua propagação e se materializam em forma de bits.

No entanto, alfabetizar digitalmente não é uma tarefa fácil e exige que os professores abracem essa novidade e pensem seu fazer pedagógico em propostas que estimulem a indagação e a criatividade dos seus alunos. A definição para "alfabetizações do século XXI", proposta pelo National Council of Teachers of English dos Estados Unidos, nos diz que a alfabetização também muda quando há mudanças na sociedade e nas tecnologias (NCTE, 2008). Esse documento destaca uma série de competências e habilidades que os leitores e escritores desse novo século terão que desenvolver. Entre elas, podemos citar a necessidade de utilizar as ferramentas e recursos tecnológicos com destreza e criticismo, permitindo que os aprendizes se tornem capazes de filtrar, projetar e compartilhar informações com diversos propósitos e que consigam ordenar, selecionar e contextualizar os aprendizados, assimilandoos e transformando-os em conhecimento. 


\section{Um computador para muitos ou um computador para um?}

Atualmente, a grande maioria das escolas públicas e particulares possui um LIE em funcionamento. Apesar da rotina de uso poder variar de uma escola para outra, a ideia de um LIE encontra-se associada à provável presença de um professor ou um técnico em informática responsável pela orientação das atividades desenvolvidas no laboratório. Nesse enfoque, o saber ligado ao uso dos computadores e sua aplicação educativa encontra-se centrado na figura desse profissional responsável pelo LIE, a quem os professores recorrem para a elaboração e planejamento de atividades para seus alunos, tendo como objetivo contemplar conteúdos e projetos de ensino sendo desenvolvidos em sala de aula.

Dentre as problematizações possíveis, levantamos, neste momento, a questão da concepção pedagógica de uso dos LIEs. Schlemmer (2006, p.36) considera que, por falta de reflexão,

a tecnologia normalmente é utilizada para digitar um texto, fazer uma apresentação de um trabalho, um gráfico, utilizar os denominados 'softwares educativos', pesquisar na internet (copiar trabalhos), jogar... Mas qual é o objetivo?

Mesmo com a inserção do laptop na modalidade 1:1, percebemos essa prática também em uma das escolas que participou da formação. De acordo com o relato de algumas professoras dessa escola, a primeira atividade que se preocupavam em desenvolver com seus alunos referia-se à prática de digitação ou a "dar tempo para que brincassem com os joguinhos” [sic ${ }^{1}$ ]. Também verificamos a utilização da tecnologia digital como uma substituição no suporte da aula, como a troca do quadro negro pela projeção de slides, por exemplo.

Isso contrasta com o que Schlemmer (op cit) apresenta ao enfatizar a relevância da proposta docente e a necessidade de que o professor seja protagonista das realidades apresentadas pelo cenário digital, desenvolvendo o processo de ensino e aprendizagem a partir dos movimentos de interação entre o sujeito e o objeto do conhecimento. Outro ponto nevrálgico abordado pela autora é a concepção pedagógica de uso do LIE. Muitas vezes ele é considerado apenas como um local para "deixar" os alunos quando algum professor falta, como prêmio, punição ou passatempo para a classe (Ibidem). Esse fato também pode ser observado no contexto do 1:1, quando observamos relatos de professores que afirmam que “deixam os alunos usar o laptop quando terminam as tarefas" [sic].

Também podemos observar aulas de informática ministradas por técnicos em informática, que podem compreender questões de ordem técnica, mas que possivelmente ignoram aspectos didáticos e pedagógicos relacionados ao uso dos computadores. Pescador (2010) questiona esse modelo de "informatização" das escolas, ponderando que essa estrutura tende a conservar um sistema de Educação individualizado, que parece não estar em acordo com as demandas do século XXI. Outra problemática é levantada por Almeida e Valente (2011). Os autores atentam para o fato de que as atividades realizadas no LIE geralmente pouco se relacionam com o cotidiano pedagógico escolar.

Os fatores elencados nos últimos parágrafos tendem a fazer com que a escola não promova a inclusão digital. Mesmo que exista a presença física de computadores dentro da escola, um uso mecânico, sem significado, sem crítica, conforme a perspectiva de Coscarelli e Ribeiro (2005), tende a não promover a inclusão digital.

\footnotetext{
${ }^{1}$ Os depoimentos transcritos foram obtidos durante os encontros presenciais de formação com os professores ou no ambiente virtual disponível para o curso de formação no e-proinfo. Não foram feitas alterações com o objetivo de corrigir possíveis erros no uso da língua portuguesa.
} 
O ProUCA tem entre seus objetivos desestabilizar essa prática, provocando mudanças nas ações centradas nos LIEs, com a presença de um laptop por aluno e por professor em cada sala de aula e pela formação continuada de docentes e gestores. Assim, a modalidade 1:1 permite a utilização concomitante por todos os alunos na escola, sem necessariamente ter que passar por agendamento de uso do laboratório. Com isso, o LIE torna-se um espaço de apoio com recursos que podem complementar atividades desenvolvidas inicialmente com os laptops.

Vale destacar a portabilidade dos equipamentos permitindo a utilização em atividades fora do contexto escolar. Na modalidade "um computador por aluno" (ou "um para um”), o tempo e o espaço da sala de aula adquirem outra dimensão, bem como o uso da tecnologia disponível a partir da inserção do laptop na sala de aula.

Um exemplo dessa utilização fora do espaço e tempo escolar se faz presente nas ocasiões em que os estudantes levam os laptops para casa, com alguma "tarefa a cumprir". Essas tarefas incluem entrevistar algum membro da família, registrando a entrevista com a utilização da webcam do laptop, fotografar partes da casa em que mora para compartilhar com os colegas, ensinar irmãos e pais a usarem recursos do laptop - em especial, os jogos.

Desse modo, entendemos que as propostas do UCA vão além do acesso à tecnologia digital, adentrando na esfera epistemológica, no sentido de promover uma reflexão e um redimensionamento do tempo, espaço e da própria estrutura pedagógica frente às realidades da cultura digital. Isso parece estar presente no depoimento de uma professora em um dos fóruns hospedados no ambiente virtual do curso de formação: "Ainda bem que começamos a perceber, que podemos mudarmos a nossa mameira de dar aula,tendo a tecnologia como um apoio didático." [sic]

As concepções da proposta tendem a promover novos movimentos na relação entre sujeito e tecnologias digitais, e tais movimentos podem levar à promoção de uma inclusão efetiva de alunos, professores, comunidade e da escola como um todo no contexto digital.

\section{Considerações finais}

Provisoriamente findadas as discussões teóricas abordadas neste trabalho, podemos inferir que ainda são necessárias pesquisas e experiências empíricas relacionadas à Educação no contexto das tecnologias digitas.

Percebemos que, em muitos momentos, a falta de reflexão pode levar a ações mal sucedidas, que não produzem inclusão digital e tampouco alterações nos panoramas pedagógicos da escola. Ações que visam unicamente à inserção de computadores na escola, sem promover um debate consistente sobre os conceitos implícitos ao uso, tendem a reproduzir um modelo educacional já existente, centrado na transmissão de informações, que, por sua vez, parece não promover a inclusão digital, a exemplo do uso do laptop com a finalidade exclusiva de digitação ou de "recompensa".

Tendo em vista o referencial teórico considerado neste artigo, observamos movimentos e ações nas escolas UCA que ultrapassam o acesso à tecnologia digital, abarcando a esfera da formação para a reflexão, e que tendem a oferecer maiores possibilidades para a promoção da inclusão digital. Talvez um grande diferencial nesse sentido venha a ser observado futuramente, com a inclusão digital dos familiares dos estudantes que levam seus laptops para casa. A liberação do polo emissor (Lemos, 2002) presente na publicação de trabalhos e projetos nos blogs das escolas (ou das professoras) dá um novo significado à produção dos estudantes, uma vez que precisam ter um leitor real em mente.

Considerando os argumentos tratados neste artigo, podemos inferir que a burocracia e o afastamento dos computadores da sala de aula, fato observado frequentemente em ações 
no modelo um computador para muitos, como, por exemplo, nos LIEs, tendem a reduzir as chances da promoção da inclusão digital. As concepções pedagógicas que permeiam esse tipo de ação, muitas vezes, fazem com que o professor não utilize os recursos tecnológicos digitais ou então faça um uso sem uma proposta pedagógica significativa.

O simples acesso à tecnologia digital, que não promova o desenvolvimento do pensamento crítico, da reflexão e da socialização parece não ser condição suficiente para a promoção da inclusão digital. Esse tipo de proposta pode instrumentalizar os sujeitos, promovendo a distribuição de cliques sem significação na tela, caracterizando um uso mecânico que não reflete uma interação crítica com o contexto digital.

Mesmo sem garantias de sucesso, iniciativas como o UCA, onde os computadores ficam próximos do contexto escolar e os professores e a equipe se encontram em constante formação, tendem a oferecer possibilidades de letramento digital e também de inclusão digital. Ponderamos novamente que o mais relevante não é a posse do laptop, mas as práticas pedagógicas desenvolvidas com o apoio deste.

Lamentamos, no entanto, que, contrariando o planejamento minucioso de qualificação dos professores que ocorreu nas duas primeiras fases do ProUCA, a fase atual do programa apenas preveja o processo de licitação para aquisição dos laptops, deixando a formação e capacitação de gestores e professores para o uso pedagógico dos novos recursos a cargo das mantenedoras. ${ }^{2}$ Orçamentos apertados na área da educação pública no Brasil possivelmente colocarão os administradores das mantenedoras diante da opção de adquirir os laptops e abrir mão de programas de formação como aquele disponibilizado gratuitamente (por se tratar de projeto piloto) no período de 2010-2012, que, segundo nossas concepções, consistia em um dos diferenciais da proposta .

Uma formação de professores delineada pela constante atitude reflexiva poderia contribuir para o desenvolvimento de um conceito crítico de uso das tecnologias digitais. Pertencente a esse conceito está a concepção das tecnologias digitais não como meras ferramentas, mas como interfaces passíveis de auxiliar o professor em sua prática pedagógica, como suporte para a pesquisa, socialização, criatividade e criticidade. Deste modo, parece-nos que seria possível o desenvolvimento de um partilhar dos mesmos direitos e deveres dos cidadãos já inclusos e também o exercício da "cibercidadania", que, segundo nossos pressupostos teóricos, indicam a efetiva inclusão digital do sujeito.

\section{Referências Bibliográficas}

ALARCÃO, I. Professores Reflexivos em uma escola reflexiva. $5^{\mathrm{a}}$ ed. São Paulo: Cortez, 2007. 102p.

ALARCÃO, I. A Escola Reflexiva. p.15- 30. In: ALARCÃO I. (org.) Escola reflexiva e nova racionalidade. Porto Alegre: Artmed, 2001.

ALMEIDA, M. E. B.; VALENTE, J. A. Tecnologias e currículo: trajetórias convergentes ou divergentes? São Paulo: Paulus, 2011. 9p.

ALMEIDA, M.E.B. Transformações no trabalho e na formação docente na educação a distância on-line. Aberto, Brasília, v. 23, n. 84, p.67-77, nov. 2010.

COLL, C. e MONEREO, C. Educação e aprendizagem no século XXI. p.15-46. In: COLL, C. e MONEREO, C. (org). Psicologia da Educação Virtual: aprender e ensinar com as tecnologias da informação e da comunicação. Porto Alegre: Artmed, 2010.

COSCARELLI, C. V.; RIBEIRO, A. E. (orgs). Letramento Digital: aspectos sociais e possibilidades pedagógicas. Belo Horizonte: Ceale; Autêntica, 2005. 244p.

\footnotetext{
${ }^{2}$ Ver medida provisória a esse respeito disponível em http://www.uca.gov.br/institucional/noticiasLei12249.jsp Acesso em 03 maio 2013.
} 
EGLER, C., COSTA, A. Interação social e tecnologia na escola. p.11-20. In: SAMPAIO, F.; ELIA, M. (Orgs.). Projeto um computador por aluno: pesquisas e perspectivas. Rio de Janeiro: NCE/UFRJ, 2012. 260p.

LEMOS, A. Cibercultura, tecnologia e vida social na cultura contemporânea. Porto Alegre: Sulina, 2002. 320 p.

LÉVY, P. Cibercultura. Tradução de Carlos Irineu da Costa. São Paulo: Editora 34, 1999. $264 \mathrm{p}$.

NCTE - National Council of Teachers of English. Toward a Definition of 21st Century Literacies. 2008. Disponível em <http://www.ncte.org/about/gov/129117.htm> . Acesso em 09 jul. 2011.

PERRENOUD, P. Dez novas competências para ensinar. Tradução de Patrícia Chittoni Ramos. Porto Alegre: Artes Médicas Sul, 2000. 192p.

PESCADOR, C. M. Como aprendem os nativos digitais em suas interações em redes hipermidiáticas. p.79-95. In. SOARES, E.M.S.; LUCHESE, T.A. Educação, educações....Caxias do Sul: Educs, 2010.

PRADO, M.E.B.B.; BORGES, M.A.F. e FRANÇA,G. O uso do laptop na escola: algumas implicações na gestão e na prática pedagógica. p.60-72. In ALMEIDA, M. E. B. e PRADO, M. E. B. (org.). O computador portátil na escola: mudanças e desafios nos processos de ensino e aprendizagem. São Paulo: Avercamp, 2011.

PRENSKY, M. O papel da tecnologia no ensino e na sala de aula. Tradução Cristina M. Pescador. In Conjectura, Caxias do Sul, v. 15, n. 2, p.201-204, maio/ago. 2010. disponível em $<$ www.ucs.br/etc/revistas/index.php/conjectura/article/view/335/289>, Acesso em 01 set. 2010.

SCHLEMMER, E. O trabalho do professor e as novas tecnologias. Revista Textual, Porto Alegre, v. 1, n.1, 33-42, Set. de 2006.

TAKAHASHI, T. (Org.). Sociedade da Informação no Brasil - Livro Verde. Brasília: Ministério da Ciência e Tecnologia, 2000. 231p.

TEIXEIRA, A.C. Inclusão Digital: novas perspectivas para a informática educativa. Ijuí: Unijuí, 2010. 152p.

VALENTE, J. A. Um laptop para cada aluno: promessas e resultados educacionais efetivos. p.20-33. In ALMEIDA, M. E. B. e PRADO, M. E. B. (org.). O computador portátil na escola: mudanças e desafios nos processos de ensino e aprendizagem. São Paulo: Avercamp, 2011. 